\title{
Study on distribution blocking system in a northern city of China by using a hydraulic model
}

\author{
Yang Feng ${ }^{1}$, Feng Chen ${ }^{2}$, WeiNing Yuan ${ }^{1}$, Hao $\mathrm{Fu}^{1}$, Hang $\mathrm{Li}^{1}$ Chunsheng \\ Zhang $^{1}$, Tong Wang ${ }^{1,3}$, Ming Zhao ${ }^{4^{*}}$,Dong Yang ${ }^{3}$ \\ ${ }^{1}$ School of Environmental Science and Engineering, Chang' an University, Xi'an, 710054, China \\ ${ }^{2}$ Jinan Water Group Co, Ltd, 250012, China \\ ${ }^{3}$ Tianjin Sambo Water Technology Co, Ltd. Tianjin, 300070, China \\ ${ }^{4}$ School of Municipal and Environmental Engineering, Harbin Institute of Technology, Harbin, \\ 150001, China \\ email: zhming1188@126.com
}

Keyword: Water Supply Network; Hydraulic Model; Distribution Blocking System (DBS)

\begin{abstract}
WNW7.0, software for water distribution analysis and design, is used to establish the hydraulic model of water distribution system in a northern city of China, and to analysis the changes of pressure and water quality in the water distribution system after applying single DBS and double DBS. The results showed that the pressure ranges in the distribution system trended to be more equal and water quality had been improved greatly using the developed DBS method.
\end{abstract}

\section{Introduction}

With the rapid economic growth of China and the continuous expansion of city, the scale of urban water supply network has also been increased. Water supply enterprises also entered a period of "strengthening management and improving efficiency". The user's request for the quantity and quality of water improvement also increased the difficulty of running water supply system [1]. Using the analysis software to establish the dynamic hydraulic model of the water supply network, applying the model tool to manage and maintain the water supply network is the future development trend.[2]

DBS (distribution blocking system, DBS) is the idea first proposed by Professor Hongbin Zhao from Harbin Institute of Technology in 2001, it is not the general concept that transforming the original pipe network into a convenient flow measurement of the DMA zone, but in considering of the water pressure, water quantity and quality factors, realizing water supply of the network and functional separation of water distribution pipes after the partitioning, forming a hierarchical water supply system.

The practice has proved that the distribution blocking system has a significant effect on reducing Non Revenue Water (NRW), balancing the pressure of pipe network and improving the reliability of water supply. Major advantages of the DBS are:

1) The implementation of distribution blocking system is an important way to reduce power consumption, reduce the wastage, improve the efficiency of water supply.[3] The optimization of pipe network pressure partition running mode make the network pressure more balanced in the 24 hours of a day, we can reduce water pressure in certain pressure areas, reduce leakage loss, radically reduce the difference between the production and marketing through the simulation of hydraulic model in some periods under the premise of meeting water pressure needs of the users.

2) High pipe network pressure is an important cause of pipe explosion accident, so reducing

Fund project: Research and Demonstration on Key Technologies of Intelligent Management System for Urban Water Supply Network during12th Five-Year Plan Period (NO: 2014ZX07406003) 
the pressure of water supply can not only reduce the leakage loss, but also effectively reduce pipe explosion accident. When an subsystem accident happens, it has little influence on the whole system, and the operation safety of the pipe network is improved.[4]

3) Simplifying the function of main pipes (only shoulder the function of water transfer to other areas), could decrease local head loss, reduce the water age, so as to improve the end of pipe network residual chlorine concentration, effectively to improve network quality[5].

4) When urban scale continues to expand and it's need a pipe network expansion, the only additional district (or district) can correspond to it and the network has strong adaptability.

\section{The Steps of DBS by Using Hydraulic Model}

Based on blocking concept of hierarchical characteristics of water supply network, a hydraulic model was established by the WNW7.0 software. Analysis of multi-level structure of the pipe network, simulation of the network partition scheme can be used to assess the performance of DBS.

$1^{\text {st }}$ step: Examination of the number of hierarchical pipe network. The block size can be determined by considering he conditions of network scale, reliability requirements and financial situation. The double DBS system (2 levels) in China may be necessary: the first level is to achieve reasonable water distribution; the second one is aim to measure flow-rate, pressure control and improve water quality [6].

$2^{\text {nd }}$ step: Delimitation of block scale. When the scale of the block is designated, the structure characteristics of the pipeline network should be considered sufficiently, and patterns of every layers of the conception diagram should be analysis. WNW can be used to divide the water supply region to achieve the first level of water supply system partition, the second and the third level will be located within the first level area, in order to form the area of the water supply range of DBS. Large transmission mains as the block boundary, which can reduce the mixing water supply areas, effectively improve the water quality. In addition, it should also consider the regional terrain features, natural and man-made obstacles, such as river basin, railways, mountains, population density, etc.

$3^{\text {rd }}$ step: Determination of reasonable influent point. The number of the water inlet is related to the water pressure, flow and water supply safety. For serious regional independence, it should be single influent point. Although beneficial to determine the point of pressure control, but at the time of the accident, rather than multiple-influent can guarantee the safety of the water supply. It is generally recommended to use two inlets.

$4^{\text {th }}$ step: Assessment of results. Using WNW software to evaluate the rationality of the DBS plan. Simulation of rationality of evaluation division scheme using WNW, including the balance of the water pressure, residual chlorine and water age, and further improve the plan. At the same time, clear the main pipe, water distribution pipe, for easy to manage and install the valve, water meter, etc. In addition, the pipeline at the end parts of the distribution system should form a ring or set drainage to improve water quality, prevent the formation of "dead water region".

\section{DBS Design in A Northern City of China}

Water supply network of J city covers more than $300 \mathrm{~km} 2$, the capacity of the supply system is 1.05 million tons/day, and the service population is 3.2 million. $\mathrm{J}$ city mainly by the three waterworks, that is, A, B and C. A water supply capacity of Waterworks is $216^{\prime} 000$ million tons per day. B is $294^{\prime} 000$ tons per day, C is $36^{\prime} 000$ tons per day. Because C waterworks area is small, so one block is applied. J city, lying southeast to northeast tilt, East West High low, hypsography has great disparity. A supply area of the terrain is relatively flat, B supply area topography more ups and downs. Based on the balance pressure, the direction of blocking is from south to north. The network model for DBS of the establishment with DN200 above the pipeline, in order to improve the accuracy of the model, after the hydraulic calculation, adding some DN200 following pipe, which has a great influence on the hydraulic condition of the pipe network. 
Taking into account the complexity of the network, the DBS cannot be a step in place, it should be implemented step by step. The project will be divided into two areas of water supply area.

First Stage. J city water supply pipe network is mainly from waterworks A and B. It is important to establish detailed models of complex hydraulic system, to carry out dynamic simulation network and analyze flow in different time by using WNW software. Tracing the water supply line, if the water from the pipeline $40 \%$ from the A water plant, which is regarded as the scope of the A water supply area. Compared to A water supply region and B water supply area, the average elevation of the former is lower than that of the latter, in order to balancing regional water supply pressure, fully considering the use of existing valves and flow meters, mainly according to the water supply boundary of A and B waterworks, network was divided into two first level metering zones. In order to save costs, the first level of the program would be divided into two water supply area by cutting off the current situation of the valves and setting the regional emergency contact tube or flow meter. Area A close 23 valve, setting 2 influent point. Area B close 43 valve, setting 4 influent point. There are 23 connecting pipe between two areas.

Second Stage. Using WNW of function separation of the pipeline, identify the main pipe, clear pipeline function of water supply and water distribution, limiting large transmission mains with water distribution. Pipe flow is determined by the diameter of the main pipeline in the region, the scale of design partitions. On the basis of first level measurement region, according to the ground elevation, pressure boundary, existing water supply capacity and other factors, it will be divided into three sub A water metering zone namely A1, A2, A3, B is same.

In B3 district, water booster pump station Baliqiao is in special way. When Baliqiao as a booster pump station, B to its water supply, which may be a separate area for B3, when Baliqiao as a water plant, its water use groundwater, and B its water supply mixed, so as to achieve equilibrium pressure and reduce energy consumption.

Determining reasonableness. On the basis of the actual pipe network system features consistent dynamic model, using WNW software, according to the partition scheme, limiting main pipe water distribution on the part of the implementation of the pipeline break gates, alteration or additions of water supply facilities, water points to determine the location, at the same time there are hydraulic simulation calculation, including the analysis of the equilibrium pressure, water age and residual chlorine concentration after DBS.

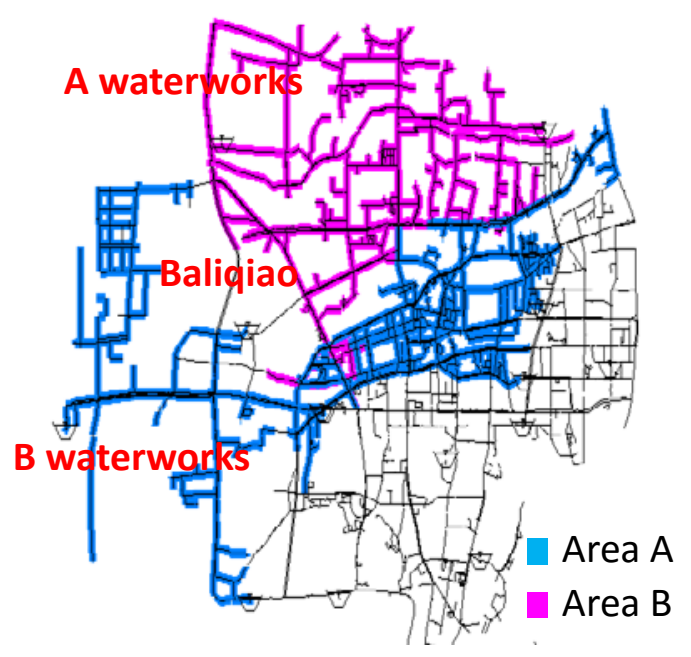

Fig.1Diagram of water supply line

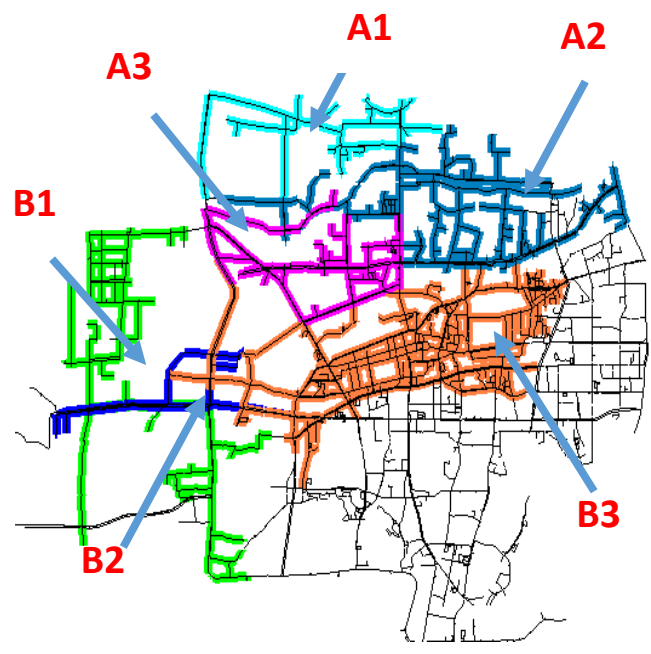

Fig.2 Schematic diagram of DBS

\section{Analysis of the Results}

According to the results of a series of studies conducted by the researchers of the United Kingdom and Japan, $\left(\mathrm{Q}_{\mathrm{up}}\right)_{j}$ and $H_{j}^{s}$, in line with the following relationship: 


$$
\left(Q_{u p}\right)_{j}=\lambda_{j}\left(H_{j}^{\prime}\right)^{1.18}
$$

where: $Q$ is water leakage; $H$ is pressure head.

Pressure: From the above equation, the amount of leakage and pressure is a positive. Hydraulically calculated in the model, the maximum pressure of water area has decreased, the lowest pressures have increased, the average pressure decreased, the pressure is more balanced, so that is conducive to saving energy, reducing pipe break and leakage accident. Pressure changes after DBS are shown in the tables below.

Tab.1 Before and after comparison of pressure in Plant A

\begin{tabular}{cccccccccc}
\hline \multirow{2}{*}{ DBS } & \multicolumn{3}{c}{ Average $\left(\mathrm{mH}_{2} \mathrm{O}\right)$} & \multicolumn{3}{c}{ Max $\left(\mathrm{mH}_{2} \mathrm{O}\right)$} & \multicolumn{3}{c}{ Min $\left(\mathrm{mH}_{2} \mathrm{O}\right)$} \\
& Before & After & Changes & Before & After & Changes & Before & After & Changes \\
\hline General & 27.5 & 27.3 & $0.2 \downarrow$ & 41.6 & 39.9 & $1.7 \downarrow$ & 7.6 & 9.0 & $-1.4 \uparrow$ \\
Peak & 28.3 & 30.0 & $-1.7 \uparrow$ & 43.9 & 43.9 & 0 & 7.9 & 11.7 & $-3.8 \uparrow$ \\
Low Peak & 30.8 & 30.3 & $0.5 \downarrow$ & 44.9 & 41.9 & $3 \downarrow$ & 10.9 & 11.9 & $-1 \uparrow$ \\
\hline \multicolumn{3}{c}{ Tab.2 Before and after comparison of pressure in Plant B } \\
\hline \multicolumn{1}{c}{ Average $\left(\mathrm{mH}_{2} \mathrm{O}\right)$} & \multicolumn{7}{c}{ Max $\left(\mathrm{mH}_{2} \mathrm{O}\right)$} \\
DBS & Before & After & Changes & Before & After & Changes & Before & After & Changes \\
\hline General & 26.5 & 27.1 & $-0.6 \uparrow$ & 60.9 & 61.1 & $-0.2 \uparrow$ & 7.6 & 9.3 & $-1.7 \uparrow$ \\
Peak & 26.7 & 24.9 & $1.8 \downarrow$ & 55.6 & 55.4 & $0.2 \downarrow$ & 7.8 & 6.9 & $0.9 \downarrow$ \\
Low Peak & 29.3 & 30.5 & $-1.2 \uparrow$ & 59.5 & 59.9 & $-0.4 \uparrow$ & 10.6 & 13.3 & $-2.7 \uparrow$ \\
\hline
\end{tabular}

Residual Chlorine. According to the national drinking water quality guideline, chlorine concentration $C$ in the any points of pipe network should not less than $0.05 \mathrm{mg} / \mathrm{L}$. When $C>0.3$ $\mathrm{mg} / \mathrm{L}$, the water quality of pipe network may be satisfied. Before blocking, average chlorine concentration at the network node is $0.334 \mathrm{mg} / \mathrm{L}$, after blocking, the value is $0.422 \mathrm{mg} / \mathrm{L}$. The number of node chlorine below $0.05 \mathrm{mg} / \mathrm{L}$ reduced $27.51 \%$, higher than $0.3 \mathrm{mg} / \mathrm{L}$ nodes increased $35.96 \%$, water quality has been greatly improved.

Fig.3 Diagram of The residual chlorine concentration distribution in A and B

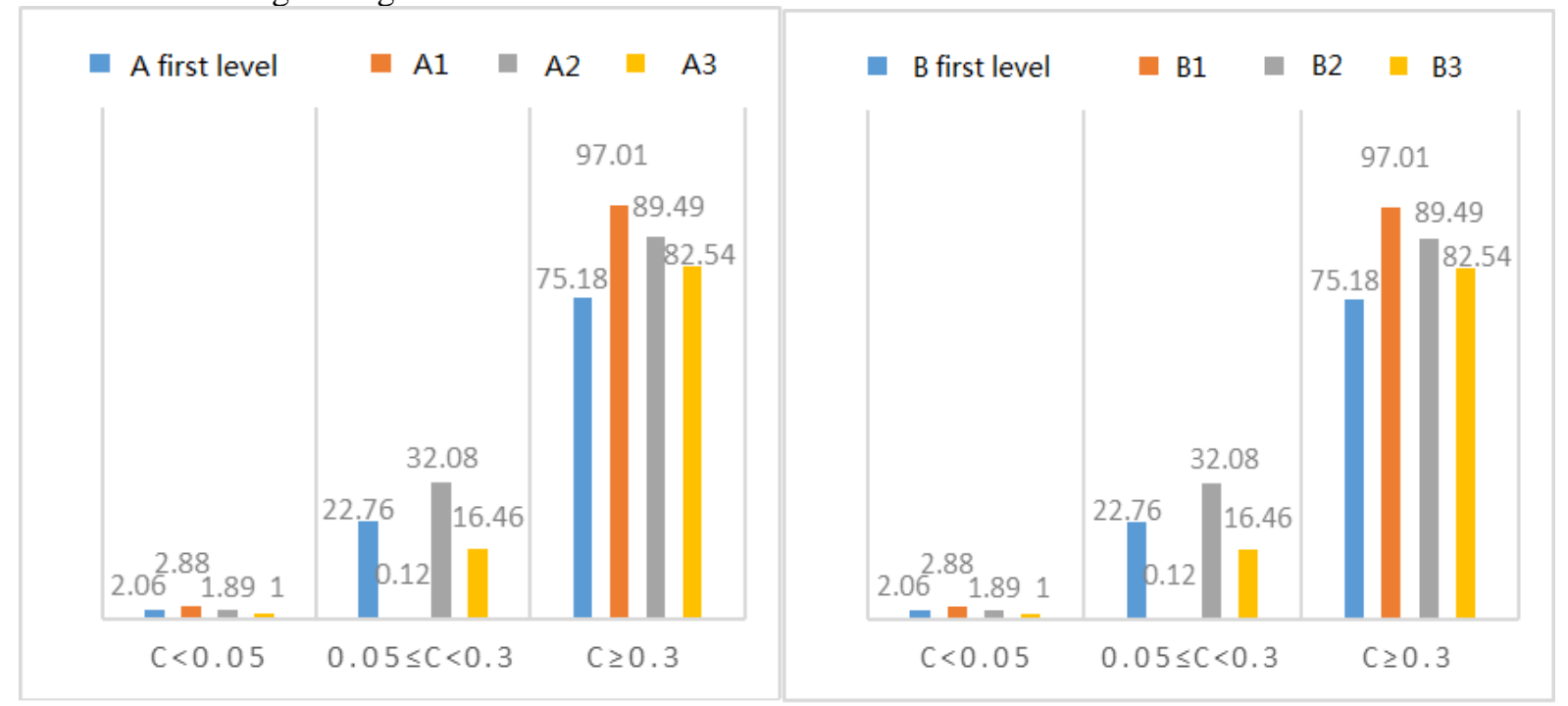

Water age. Two important indicators of the evaluation quality of water are water age and the residual chlorine. According to the national drinking water specification, water age $T$ less than or equal $45 \mathrm{~h}$ is the first water quality, age greater than 45 and less than $58 \mathrm{~h} \mathrm{~T}$ is the second water quality, water age greater than or equal $58 \mathrm{~h} \mathrm{~T}$ is three water quality. The average age of the water before the block is $30.228 \mathrm{~h}$, after a block of average water age is $24.743 \mathrm{~h}$. Water age in the first level accounted for more than $96 \%$, water age maximum can be shortened $5.81 \%$. Water quality data after DBS is summarized in Table 3, which shows that water quality has improved after DBS. 
Tab.3 Quality after DBS

\begin{tabular}{cccc}
\hline & Block & Water age (hours) & $\begin{array}{c}\text { Residual chlorine } \\
(\mathrm{mg} / \mathrm{L})\end{array}$ \\
\hline \multirow{5}{*}{ A waterworks } & The first & 24.74 & 0.422 \\
& A1 & 22.97 & 0.456 \\
& A2 & 29.38 & 0.464 \\
& A3 & 16.95 & 0.512 \\
B waterworks & The first & 27.62 & 0.443 \\
& B1 & 18.91 & 0.687 \\
& B2 & 30.82 & 0.407 \\
\hline
\end{tabular}

\section{Conclusion}

DBS needs to be established based on a network based hydraulic model. By using DBS method, the pressure ranges in the distribution system trended to be more equal and water quality had been improved greatly. Moreover, reduction of NRW can be achieved.

\section{Acknowledgement}

In this paper, the research was sponsored by a grant from the National Key Technologies R \& D Program of China during the 12th Five-Year Plan Period (No.2014ZX07406003), and special thanked to Tianjin Sambo Water Technology Co., Ltd. and Professor Hongbin Zhao of Harbin Institute of Technology.

\section{References}

[1] S Park, SY Jung. Developing efficient management strategies for a water supply system using system dynamics modelling. [J].Seminars in Cancer Biology, 2013, 31(3):189-208.

[2] AMF Diniz, CHDO Fontes, CAD Costa, GMN Costa. Dynamic modeling and simulation of a water supply system with applications for improving energy efficiency.[J].Energy Efficiency, 2014, 8(2):1-16.

[3]Aoyama T, Kawamoto S. Establishment of water distribution block system in OSAKA municipal waterworks. [J].Water Supply, 1999, (17):269-275.

[4] JE Shortridge, SD Guikema. Public health and pipe breaks in water distribution systems: Analysis with internet search volume as a proxy. [J].Water Research, 2014, 53(8):26-34.

[5] TR Wallin, DJ Schaeffer. Illinois redesigns its ambient water quality monitoring network. Environmental Management. [J].1979, 3(4):313-319.

[6] YC Su, LW Mays, N Duan, KE Lansey. Reliability-Based Optimization Model for Water Distribution Systems. [J]. Journal of Hydraulic Engineering, 1987, 113(12):1539-1556. 